\title{
The relationship between in-store marketing and observed sales for organic versus fair trade products
}

\author{
Erica van Herpen • Erjen van Nierop • \\ Laurens Sloot
}

Published online: 15 December 2011

(C) The Author(s) 2011. This article is published with open access at Springerlink.com

\begin{abstract}
To stimulate sales of sustainable products, such as organic and fair trade products, retailers need to know whether their in-store instruments effectively enhance market shares. This study uses sales data and a multilevel modeling approach to explain the market shares of sustainable products according to shelf layout factors, price level, price promotions, and consumer demographics. It argues that the effect of these variables differs between organic versus fair trade products, as buying motives might differ, organic buyers tend to be more loyal, and price is a more informative signal of quality for organic products. Results show that the number of facings has a positive relationship with the market share of fair trade brands, but not with the market share of organic brands. The same holds for the price difference with the leading brand, which is important for fair trade brands but not for organic brands. In contrast, an arrangement of the product category by brand is associated with higher market share for organic brands but not for fair trade brands. Additionally, placement at eye level and clustering of items benefits both types of sustainable brands, whereas they appear to be not very sensitive to price promotions. Finally, higher sales of sustainable products are found in areas where the customer base is older and has a higher education level.
\end{abstract}

\footnotetext{
E. van Herpen

Wageningen University, Marketing and Consumer Behavior Group, PO Box 8130, 6700 EW Wageningen, The Netherlands

e-mail: erica.vanherpen@wur.nl

E. van Nierop $(\bowtie) \cdot$ L. Sloot

Marketing Department, University of Groningen, Nettelbosje 2, 9747 AE Groningen, The Netherlands

e-mail: j.e.m.van.nierop@rug.nl

L. Sloot

e-mail: 1.m.sloot@rug.nl

E. van Nierop $\cdot$ L. Sloot

EFMI Business School, Heiligenbergerweg 5, 3833 AC Leusden, The Netherlands
} 
Keywords Organic $\cdot$ Fair trade $\cdot$ Shelf layout $\cdot$ Price promotions · Market share ·

Sales data

\section{Introduction}

As consumer consideration for the societal impacts of products has increased (Auger et al. 2008), organic and fair trade products have become part of mainstream food retailing. The ability to influence the sales of these sustainable food products grants supermarkets a key role in the development of "a greener, healthier, and fairer food system" (Sustainable Development Commission 2008). In this sense, many retailers not only carry organic and fair trade products but actively attempt to stimulate their sales using in-store marketing tactics (Just-Food 2004).

To promote such sales, retailers need to identify the key drivers. Interestingly, although organic and fair trade products have often been lumped together as "green" products or as products concerning an ethical issue (e.g., Tanner and Wölfing Kast 2003; De Pelsmacker et al. 2005a), important differences exist between the two. Specifically, consumer motives for buying organic or fair trade products differ. Organic products are often bought not only for environmental motives, but also for personal motives such as health or taste (Schifferstein and Oude Ophuis 1998). The latter are even considered the main purchasing motives for organic products (Cottingham and Winkler 2007). The primary motivation to buy fair trade products, in contrast, is to benefit the world's poor (Bowes and Croft 2007). Possibly as a result of this, important differences between purchases of organic versus fair trade products have been observed. Whereas organic buyers are identified as a small core of big spenders, willing to go to extra length to buy these products (Cottingham and Winkler 2007), the fair trade consumer base is considered more diverse and less willing to spend effort in search for these products (De Pelsmacker and Janssens 2007; Lamb 2007). This implies that the market share of fair trade brands may rely to a larger extent on their visibility on the shelf than the market share of organic brands.

Furthermore, consumers often rely on information signals to determine brand value and credibility, and in a supermarket context, marketing mix instruments can serve as such signals (Erdem 1998; Erdem and Swait 2004; Ngobo 2011). An important signal of product quality is price (Erdem et al. 2008). Yet, whereas a premium price can indeed signal quality in the case of organic products, it may mainly signal higher wages for laborers in the case of fair trade products. Consumers may thus respond differently to price premiums for organic versus fair trade brands.

The present study aims to identify key drivers of the market share of organic and fair trade brands, and to investigate differences for these two types of products. Specifically, it examines three groups of variables: (1) shelf layout, (2) price and price promotions, and (3) consumer demographics. To our knowledge, this is the first study directly comparing organic and fair trade brands, to show how the effectiveness of marketing mix variables differs between these products. It focuses on aggregate data about consumer purchases, a relatively new perspective in literature on sustainable products, which tends to employ willingness-to-pay measures or self-reported attitudes and behavior (Auger et al. 2008; Thompson 1998; Loureiro and Lotade 2005) rather than actual product sales. Yet consumers overestimate their willingness to pay for products (Ajzen et al. 2004), and self-reported positive attitudes cannot ensure high sales levels 
(Vermeir and Verbeke 2006). Furthermore, the effectiveness of in-store factors, such as shelf space and shelf arrangement, are difficult to assess using survey data, even though they are potentially very important (Drèze et al. 1994). Our study thus extends existing literature in two important ways: first, by directly comparing the impact of marketing instruments for organic and for fair trade sales, and second, by providing a rich analysis of this impact using aggregate sales data combined with information on shelf layout, price and price promotions, and store service area.

\section{Shelf layout}

\subsection{Shelf space}

The allocation of shelf space is of vital importance to retailers, because it influences both inventory return on investment and customer satisfaction (Lim et al. 2004). In recent decades, this influence has stimulated experiments to measure the effect of shelf space on sales, as well as the development of models designed to solve the shelf management problem (for a review, see Van Nierop et al. 2008). The general insight from prior research is that the amount of shelf space allocated to a product, in relation to that of the total product category, positively affects product sales (Desmet and Renaudin 1998). Yet, the positive effects of additional shelf space can taper off, such that increasing the number of facings for a product has a positive but marginally diminishing effect on product demand (Chandon et al. 2009). Drèze et al. (1994) use field experiments to show that most products are even allocated more shelf space than would be expected based on their market share, and that the number of facings is one of the least important success factors among shelf layout factors. However, because the majority of studies find positive effects of shelf space, we expect that, overall, the market share of both organic and fair trade brands relates positively to the proportion of the category shelf space allocated to these brands.

Additionally, we expect differences between organic and fair trade products. The shelf space devoted to products is related to their visibility on the shelf. Given that the visibility of fair trade products is considered vital to their sales (De Pelsmacker and Janssens 2007), this may matter more for fair trade products than for organic products. After all, the consumer base of organic enthusiasts may be willing to spend more effort to locate these products on the shelf (Cottingham and Winkler 2007). Hence, the market share of fair trade brands may relate more positively to the proportion of the category shelf space allocated to these brands than the market share of organic brands.

\subsection{Location on the shelf}

Whereas the effect of shelf space has been examined thoroughly, location issues have received much less research attention (as noted by Campo and Gijsbrechts 2005), even though the location of a product on the shelf has an important influence on its sales. For its vertical location, eye level is typically best; with regard to the horizontal location, the optimal position is less clear (Chung et al. 2007; Drèze et al. 1994). Some evidence suggests that a location toward the beginning of the shelf (i.e., closer to the main aisle) may be better, whereas a location in the middle of the 
displayed product category is worse, possibly because consumers can reach the product quicker coming from the main aisle (Van Nierop et al. 2008). The inferior performance of the center position may not generalize to all contexts though; it depends on assortment complexity (Chung et al. 2007). Van Nierop et al. (2008) show that price sensitivity is lower for products that are placed on the middle of the shelf. Because both organic and fair trade products are often priced higher than conventional products, this lower price sensitivity could help their sales. Also, Chandon et al. (2009) revealed that being in the center of the shelf helps products get noticed and, ultimately, bought. This point seems especially relevant for organic and fair trade products, which generally lack the consumer awareness levels that national brands enjoy. Generally thus, a location closer to eye level and a location in the center of the shelf space assigned to the product category rather than toward the end of the category shelf space should both increase the market share of organic and as well as fair trade brands. Based on the observation that organic buyers appear more willing to spend effort to locate these products than fair trade buyers, we suspect that this effect may be stronger for fair trade than for organic brands. Being in a highly visible location implies less effort on the side of the consumer in locating the products on shelf and this should stimulate fair trade sales more than organic sales.

\subsection{Clustering of organic or fair trade products}

Within a product category, a single brand often offers multiple flavors and/or sizes (Boatwright and Nunes 2001). A brand of fair trade chocolate bars, for example, might provide different varieties such as dark almond and milk hazelnut. When these items cluster together and form a "block" in the product category, consumers may notice them more readily, whereas if each organic or fair trade item is placed next to a comparable conventional product, it may be less distinctive. Clustering also could increase the identification of organic or fair trade as a relevant attribute and the importance weight that consumers assign to it (Desrochers and Nelson 2006). As a result, the market share of sustainable brands should be higher when the brand items are clustered together on the shelf rather than dispersed throughout the product category. Again, the market share of fair trade brands may be influenced to a larger extent than the market share of organic brands, given the higher importance of visibility for fair trade brands.

\subsection{Arrangement of products throughout the assortment}

The primary arrangement used for the overall product category can take many forms, regardless of whether sustainable products are clustered. For example, some stores might place the items of the sustainable brand together but still arrange the category according to flavor or price level. This category arrangement may influence sales of sustainable products. After all, in any product category arrangement, the organizing attribute is likely to increase in salience (Areni et al. 1999). Thus, the ethical value of a fair trade brand, or the health value associated with an organic brand, may work to their advantage if the total product category is arranged by brand. In this case, brand becomes salient for consumers, who then compare various brands and focus on their added value. An arrangement based on flavor might not have the same effect, 
because consumer attention focuses on flavor rather than the added value of sustainable products. Furthermore, an arrangement based on an attribute on which sustainable brands perform poorly is likely to be detrimental to their market share. Because sustainable products typically have higher prices than conventional products, arranging products by price may draw attention to their premium prices and decrease their market share. We thus expect that the market share for sustainable brands is higher when the total product category is arranged according to brand, and lower when the total product category is arranged according to price, compared with other arrangements. Given that the added value of organic brands (i.e., taste, health) is more personally relevant to consumers, we speculate that an arrangement on brand increases market share more for organic than for fair trade brands. In contrast, for an arrangement on price, the negative effect on market share is speculated to be smaller for organic brands, for which a high price is more likely to signal quality as the next section will elaborate upon.

\section{Price and price promotions}

\subsection{Premium prices}

The relatively high price associated with organic and fair trade products can limit their demand. Even if consumers will pay a premium for organic or fair trade products, studies that examine this willingness to pay consistently show that the percentage of consumers who want to buy these products increases sharply when price premiums are smaller (Wier and Calverley 2002). Consequently, a lower price premium for sustainable products may induce consumers to buy them, and may increase market share.

Consumers may be more willing to pay a high price when they see this high price as a signal for quality. Although several studies indicate that a premium price is a deterrent for organic brands (Loureiro and Lotade 2005; Verhoef 2005; Wier and Calverley 2002), the signaling value of price may work better for organic than for fair trade brands. Specifically, Wathieu and Bertini (2007) have argued that price can act as a stimulus for recategorization, whereby organic products are more likely to be perceived as a health food when a price premium is attached. Given that health is considered one of the main purchasing triggers for organic products, a (moderate) price premium may actually stimulate sales and market share for these products. The price premium induces consumers to think about the offering and this can increase their willingness to pay. Price is then used as a signal of product quality (Erdem et al. 2008; Yoo et al. 2000). In empirical support, Ngobo (2011) finds an inverted Ushape effect of price for organic products. For fair trade products, in contrast, a price premium does not signal a higher quality of the inputs in the production process but a more fair price for the laborers. Premium prices then do not necessarily signal quality. Thus, based on these considerations, we expect price premiums to decrease market shares for fair trade products, but not necessarily for organic products.

\subsection{Price promotions}

A price promotion for sustainable products can temporarily lower the price gap between sustainable and conventional products and stimulate consumers to buy 
sustainable instead of conventional products. It may induce stockpiling among buyers of sustainable products, which can increase consumption levels, decrease brand switches, and increase repeat purchases, all of which increase the market share of the promoted product (Ailawadi et al. 2007). Yet, the effect of a price promotion may not be very strong for sustainable products. Prior research has shown that price cuts only have relatively small effects for fair trade coffee (Arnot et al. 2006), and do not appear to drive organic purchases (Ngobo 2011). It appears that ethically oriented consumers, who are likely to buy more sustainable products, respond less strongly to price cuts than do other consumers. Still, we examine whether price promotions stimulate the market share of organic or fair trade brands. There is no strong a priori expectation for differences between these two types of brands and this study will explore whether a difference can be uncovered.

\section{Demographics of the store service area}

Other factors also need to be taken into consideration. Product sales depend on local market potential and buying power, with socio-demographic variables as important indicators (Campo et al. 2000). Generally speaking, consumers with a higher income, specific age groups (i.e., middle age and older consumers), and those with higher education are more likely to buy organic and fair trade products (Ngobo 2011; Haanpää 2007; Loureiro and Lotade 2005; Thompson 1998; Zhang et al. 2008), although the size of the impact of demographics has been questioned (De Pelsmacker et al. 2005b). Thus, when stores appear in trade areas with, for example, a disproportionately large number of highly educated consumers, the market share for sustainable products should be higher. Furthermore, given the increased penetration of fair trade products across consumer groups, and their widespread marketing and availability, demographic variables may not be very effective in predicting market shares for fair trade brands (Doran 2009; Lamb 2007), and effects may thus be stronger for organic brands.

\section{Data}

Sixty outlets from a national supermarket chain were selected for this study. The chain mainly operates franchise stores, which it advises on assortment and presentation decisions depending on regional differences and store size. Franchise stores have the autonomy to deviate from these recommendations, which increases the variation in the independent variables (shelf layout, assortment, price). To obtain high variation in market shares, we selected 30 stores with relatively high $(0.9 \%)$ and 30 stores with relatively low $(0.2 \%)$ market shares for sustainable products.

Nine product categories were selected based on the presence of sustainable products, their ability to draw sales from consumers with various demographic profiles, and variation in market shares. Any brands labeled fair trade or organic represented the sustainable alternatives within a product category. All items of each sustainable brand carried this label, no brand carried both labels, and the label was not carried by any items offered by other brands in our data set. Although it is 
certainly possible to produce sustainable food products without labeling them organic or fair trade, consumers cannot easily identify such products in the store, so we do not incorporate them in our study. Within each product category, an individual outlet could carry no, one, or two different sustainable brands; there was never more than one organic and one fair trade brand in these categories. In total, we gathered 567 observations of sustainable brands across 60 outlets. Although their market share was low when averaged across all categories (including many categories without organic or fair trade brands), shares differed considerably across categories, from $0.77 \%$ for vegetables in jars to $43.57 \%$ for baby food.

A research assistant who was not familiar with our main expectations visited each outlet and coded, for each product category, how many stock-keeping units (SKU) and facings were available for the total category and for just the sustainable brands (counts); whether the sustainable products were clustered (yes/no); and how the overall assortment was primarily arranged (arranged by brand, price, or other type of arrangement). The research assistant also indicated the vertical and horizontal positions of sustainable brands in the shelf space devoted to the product category.

The retailer provided information about the market share of all sustainable brands on the store level, the price difference between the sustainable brand and the leading brand for each product category, and the price promotional intensity per sustainable brand (price cuts). These data referred to the quarter in which the store visits occurred, aggregated across 13 weeks. Furthermore, the retailer offered information about the socio-demographic profile of its stores' neighborhoods in terms of age, education, and income level. In Table 1, we provide an overview of all variables.

\section{Modeling approach}

The model estimates the relationship between the logit of market share and the variables described in the data section. Market share rather than unit sales is the dependent variable, to take into account the large differences in sales across stores. The market share of the sustainable brand in category $c$ in store $s$ is denoted $\mathrm{MS}_{s c}$. The data consist of repeated observations for the socio-demographic variables and the product categories, so we use a multilevel modeling approach, which includes additional error terms for the stores $\left(\eta_{s}\right)$ and product category $\left(\eta_{c}\right)$. The resultant model is:

$$
\operatorname{logit}\left(\mathrm{MS}_{s c}\right)=X_{s c} \beta+\eta_{s}+\eta_{c}+\varepsilon_{s c}
$$

We vary the number of levels from zero (regular regression) to two (both store and product category) and investigate which version provides the best fit.

The independent variables in the $X$-matrix are the shelf layout, price and promotion, and socio-demographic variables, as well as the type of product (coded as $1=$ organic and $-1=$ fair trade) and the interactions of each of the shelf layout, price and promotion, and demographic variables with the type of product. The main effects of shelf layout, price and promotion, and demographic variables can thus be interpreted as the discrepancy from the grand mean, that is, the overall effect of these independent variables across both organic and fair trade brands; the interaction 
Table 1 Description of the variables in the model

Variable name Variable description

Dependent variable

$\mathrm{MS}_{S c}$

Type of brand

Organic

Shelf layout variables

Relative \#facings

Vertical shelf position

On edge of category

Sustainable SKUs clustered

Arranged on brand

Arranged on price
Market share of the sustainable brand in store $s$ in product category $c$.

Whether the brand is organic (coded as 1) or fair trade (coded as -1).

Number of facings assigned to the sustainable brand, relative to the number of facings in the entire product category. This variable is mean-centered.

Number between 0 and 1 (shelf number/number of shelves), such that a lower number means a lower shelf. This variable is mean-centered. To capture possible nonlinear effects, we include the squared distance to the middle shelf (Van Nierop et al. 2008).

Whether sustainable brands are placed at the edge of the category as opposed to the middle (effect-coded where $1=$ yes and $-1=$ no).

Whether items from the sustainable brand are clustered (effect-coded).

Whether products in the entire category are primarily arranged by brand (effect-coded)

Whether products in the entire category are primarily arranged by price (effect-coded).

Price and promotion variables

Price difference with

leading brand

The price of the sustainable brand versus that of the leading brand in the category as a percentage. It is positive when the sustainable brand is more expensive.

Size of the price promotion Combination of sales and turnover data from promotional periods and nonpromotional periods. We compute the prices by dividing the turnover by sales, then compute the price promotion as (Promotional Price-Regular Price)/Regular Price.

Demographics of the store service area

Age of housewife

Age patterns in the trade area, as the percentage of housewives in three age categories: younger than 35 years, 35-64 years, and 65 years and older. Variables are mean centered and the middle category is the reference category.

Education

Percentage of people with high education (college or above), mean-centered.

Income

Percentage of people with high income (60,000 euro or higher), mean-centered.

Other variables (used as instruments in estimation procedure)

Entropy of facings

A measure of diversity of the assortment based on symmetry of the frequencies of the items in the assortment, computed as:

Entropy $=\sum_{i=1}^{N} F_{i} \log \left(F_{i}\right)$, where $F_{i}$ denotes the number of facings of brand $i$ (see also Kahn and Wansink 2004; Van Herpen and Pieters 2002).

Entropy of SKUs

effects with type of product represent the difference between organic and fair trade brands for each of these independent variables.

The $X$-matrix in Eq. 1 contains, among other factors, the relative number of facings a brand has been assigned. In practice, brands that sell well tend to earn 
many facings (Campo and Gijsbrechts 2005; Van Dijk et al. 2004; Van Nierop et al. 2008), such that the number of facings is endogenous. Therefore, we include a second equation in the model, which explains relative facings on the basis of instrumental variables (IVs). As instruments, we use SKU entropy, facings entropy, the total number of SKUs in the category, and the total number of facings in the category. The main requirement of instruments is that they correlate strongly enough with the endogenous variable (i.e., relative facings) but not strongly with the dependent variable in the main equation. The chosen instruments meet these criteria: Across the four instruments, the correlation with the dependent variable logit(MS) averages 0.07 , and the maximum is 0.24 . The instruments also correlate more strongly with the endogenous variable, such that across the four instruments, the average correlation with the number of facings is 0.40 , and the maximum equals 0.81 . The IV equation results in fitted values for relative facings, which replace the original relative facings in the main equation. This approach resolves the endogeneity problem.

\section{Estimation results}

As described in the previous section, we consider multilevel models with levels for product category, store, and both. The model with store multilevel includes dummies for the product categories. Considering the large differences in observed market shares, dummies for each of the high-share categories baby food $(43.57 \%)$, eggs $(4.89 \%)$, coffee $(7.74 \%)$, and milk $(8.05 \%)$ are introduced. ${ }^{1}$ Market shares of the other categories range between $0.77 \%$ and $1.67 \%$. Results show that a model with only the store level and the four product category dummies obtained the lowest AIC of 870, compared with models without levels $(\mathrm{AIC}=901)$, with only product category $(\mathrm{AIC}=897)$, and with both store and product category levels $(\mathrm{AIC}=872)$. Therefore, we focus on this store-level model.

To estimate the parameters in our model, we first regressed the relative number of facings on the four instruments and predicted the facings using the regression equation. To correct for the endogeneity of facings, we then included this predicted number of facings in the main model of Eq. 1. Furthermore, we included the variables described in Table 1. We also considered including both income and education, but the high correlation between these variables resulted in multicollinearity problems. Therefore, the final model includes just education; with just income, we attained similar results, except that the effects of income do not reach statistical significance ( $p=.051$ versus $p<.001$ for education). In Table 2 , we display the estimation results for the final model with multilevel on the store only. As indicated in this table, there is no systematic overall difference in market share

\footnotetext{
${ }^{1}$ We consider these categories because analysis of variance tests on market share, followed by post hoc analyses, indicated significant differences between these categories. Also, market shares were significantly different from the five remaining categories. These latter five categories did not significantly differ from one another. Noting the large market share of the baby food category, we estimated our model without this category, and parameter estimates changed only slightly. The dummy therefore captures the difference in market share very well.
} 
Table 2 Estimation results for main model

\begin{tabular}{|c|c|c|}
\hline Variable & Coefficient & $p$ Value \\
\hline Intercept & -4.599 & $<.001$ \\
\hline Product type (effect coding: $1=$ organic, $-1=$ fair trade) & 0.142 & .528 \\
\hline \multicolumn{3}{|l|}{ Shelf layout variables } \\
\hline Fitted relative facings (IV estimation) & 1.082 & $<.001$ \\
\hline Interaction fitted relative facings $\times$ product type & -0.957 & $<.001$ \\
\hline Vertical shelf position & 0.533 & .025 \\
\hline Interaction vertical shelf position $\times$ product type & 0.327 & .169 \\
\hline Squared distance to the middle shelf & -3.019 & .004 \\
\hline Interaction squared distance to the middle shelf $\times$ product type & -0.806 & .442 \\
\hline On edge of category & -0.071 & .126 \\
\hline Interaction on edge of category $\times$ product type & 0.003 & .949 \\
\hline Sustainable SKUs clustered & 0.135 & .099 \\
\hline Interaction sustainable SKUs clustered $\times$ product type & 0.032 & .662 \\
\hline Arranged on brand & 0.094 & .058 \\
\hline Interaction arranged on brand $\times$ product type & 0.146 & .003 \\
\hline Arranged on price & -0.198 & .413 \\
\hline Interaction arranged on price $\times$ product type & 0.139 & .563 \\
\hline \multicolumn{3}{|l|}{ Price and promotion variables } \\
\hline Price difference with leading brand & -0.230 & .333 \\
\hline Interaction price difference with leading brand $\times$ product type & 0.506 & .036 \\
\hline Size of the price promotion & 0.297 & .250 \\
\hline Interaction size of the price promotion $\times$ product type & -0.222 & .366 \\
\hline \multicolumn{3}{|l|}{ Demographics of the store service area } \\
\hline$\%$ of housewives younger than 35 years & -1.225 & .139 \\
\hline Interaction $\%$ of housewives younger than 35 years $\times$ product type & 0.854 & .080 \\
\hline$\%$ of housewives older than 65 years & 2.515 & .007 \\
\hline Interaction $\%$ of housewives older than 65 years $\times$ product type & 0.401 & .469 \\
\hline$\%$ of people with high education & 3.813 & .000 \\
\hline Interaction $\%$ of people with high education $\times$ product type & -0.663 & .072 \\
\hline \multicolumn{3}{|l|}{ Control variables } \\
\hline Baby food & 3.934 & $<.001$ \\
\hline Milk & 0.820 & $<.001$ \\
\hline Coffee & 1.545 & $<.001$ \\
\hline Eggs & 1.914 & $<.001$ \\
\hline
\end{tabular}

The four control variables are dummy $(0,1)$ coded

between organic and fair trade brands. The dummies that capture intrinsic differences in the market share of the product groups are all significant. The parameter for the baby food dummy has the highest value, which corresponds to the fact that this category has the highest market share. Next, we turn to the variables of interest. 


\subsection{Shelf layout}

Results for the number of facings are in line with the expectations. Across both organic and fair trade brands, the number of facings has a positive association with market share $(\beta=1.082, p<.001)$ and this effect is smaller for organic than for fair trade brands $(\beta=-0.957, p<.001)$. In follow-up analyses, the effects for fair trade or for organic separately can be examined by combining the two parameters, this is, by adding the two parameters to obtain the effect for organic brands or by subtracting the interaction parameter from the main effect parameter to obtain the effect for fair trade brands. These follow-up analyses show that the mitigation of the relationship for organic brands is such that the positive effect of facings is not significant for these brands $(\beta=0.125, p=.361)$. The effectiveness of assigning more shelf space to fair trade brands is thus as expected and in line with what has typically been found for conventional brands (e.g., Desmet and Renaudin 1998; Van Nierop et al. 2008), whereas this is not the case for organic brands. The amount of shelf space appears to be of little effect for organic brands, supporting the notion that these brands tend to appeal to a specific segment of consumers who are willing to actively search for them. Another potential reason for this result might be that the share of shelf space allocated to organic brands is often relatively high compared with their market share (in our dataset, this is true for all categories except baby food and milk). Following the principle of diminishing marginal returns, additional shelf space progressively may lead to fewer additional product sales (Chandon et al. 2009), and the effectiveness of adding shelf space might have tapered off. An examination of the ratio of share of facings compared to market share does not support this alternative reason, however, as this ratio is higher for fair trade products (8.05) than for organic products (4.44).

As expected, there is an inverted U-shaped relationship between vertical shelf position and market share, with a significant effect of both vertical shelf position and squared distance to the middle shelf $(\beta=0.533, p=.025$ and $\beta=-3.019, p=.004$, respectively). The difference between organic and fair trade brands is not significant. The best position on the shelf appears to be just above the middle ( 0.6 , where top shelf $=1$, bottom shelf $=0$ ). Taking into account the average height of consumers and the distance they typically stand from the shelf, Drèze et al. (1994) have calculated average resting positions of the eye at 49 and 55 inches for women and men, respectively. The optimal vertical position they find is 56 inches; if the top shelf is 72 inches, this finding is only slightly higher than our recommendation. Thus, in line with prior research, we find that eye level is the best vertical position for products. This appears to hold irrespective of whether it concerns organic or fair trade products.

Being on the edge of the category or in the middle has no significant relationship with market share. Whereas the scarce prior research on horizontal shelf position has provided mixed results, our results for sustainable products show no favored horizontal location.

There is a marginal positive effect of the clustering of items from the sustainable brand $(\beta=0.135, p=.099)$, with no significant difference between organic and fair trade brands. Overall, this suggests that placing the different items from a sustainable brand together may increase the market share of this brand. 
The arrangement of the total assortment of the product category also matters. An arrangement based on brand has a marginal positive effect on market share across both types of sustainable products $(\beta=0.094, p=.058)$, and this main effect is qualified by a significant interaction with type of products $(\beta=0.146, p=.003)$. As expected, arranging the product category on brand is more helpful for organic brands than for fair trade brands. Follow-up analyses show that for fair trade brands the effect of brand arrangement is not significant $(\beta=-0.052, p=.229)$. Arranging the product category on price does not significantly affect market shares, nor does it significantly differ between the two product types.

\subsection{Price and price promotion}

There appears to be no overall relationship between the price difference with the leading brand and the market share of sustainable products. In line with expectations, however, there is a significant difference between organic and fair trade products $(\beta=$ $0.506, p=.036$ ). Follow-up analyses show that price has no significant effect on market share for organic brands $(\beta=0.277, p=.206)$, but has the expected negative effect for fair trade brands $(\beta=-0.736, p=.015)$. Thus, whereas premium prices have often been mentioned as detrimental to the sales of sustainable products, both for fair trade and organic products (De Pelsmacker and Janssens 2007; Verhoef 2005; Wier and Calverley 2002), we find that this is only true for fair trade products. ${ }^{2}$

At the same time, the size of a promotional price cut appears to bear no relationship with our dependent variable. Although not as expected, this is in line with prior research were promotions also did not significantly influence organic purchases (Ngobo 2011).

\subsection{Demographics of the store service area}

As for the socio-demographic characteristics of the customer base, we find the following. For the percentage of housewives younger than 35 years, the main effect was not significant, but there is a marginally significant interaction with type of product $(\beta=$ $0.854, p=.080)$. Follow-up analyses show that for organic products the relationship is not significant $(\beta=-0.372, p=.346)$, but for fair trade products there is a negative effect $(\beta=-2.079, p=.013)$. When more young people live in a certain area, market share of fair trade products goes down. For the percentage of housewives older than 65 years, there is a positive main effect only $(\beta=2.515, p=.007)$, with no significant difference between organic and fair trade products. The higher market share of sustainable brands for stores with an older customer base aligns with the argument that consumers' sense of involvement and responsibility in their communities increases with age, though it also could be due to cohort effects (Roberts 1996). It is also consistent with prior empirical findings (Ngobo 2011; Haanpää 2007; Zhang et al. 2008).

The percentage of people with high education (college or higher) has a positive relationship with market share $(\beta=3.813, p<.001)$, and follow-up analyses show

\footnotetext{
${ }^{2}$ We tested for an inverted-U effect between price and market share, but found no evidence for this in our data ( $p=.60$ for the squared term of price difference with the leading brand). A possible interaction of this squared term with type of product could not be estimated due to collinearity problems.
} 
that this is the case for both organic $(\beta=3.150, p<.001)$ and fair trade products $(\beta=4.477, p<.001)$. The effects are marginally stronger for fair trade products, as can be seen from the interaction effect $(\beta=-0.663, p=.072)$.

\section{Discussion}

Our study compares organic and fair trade products, which extends a recent study examining differences between sustainable and conventional products (Bezawada and Pauwels 2010). Specifically, Bezawada and Pauwels have found that consumer responses to both assortment increases and price decreases are stronger for organic than conventional products. Contributing to this, the current study has shown that generalizing across sustainable brands, lumping organic and fair trade brands together, is inappropriate, as the effect of shelf layout variables and price levels differ between these products.

Increasing the number of facings appears effective for fair trade products. This corresponds to our conjecture that fair trade products need visibility to be noticed and bought. Organic products, in contrast, appear not to benefit from increased numbers of facings. Because organic products primarily appeal to a consumer segment that is willing to search for them, possibly due to the relevance of more personal motives such as taste and health, the amount of shelf space may matter less.

Shelf layout, in terms of both where sustainable products are located on the shelf and how the shelf is arranged, matters for sustainable products as well. As has been found in several studies (Van Nierop et al. 2008), a vertical location at eye level is optimal. This effect appears so pervasive that it affects organic and fair trade brands equally. Clustering sustainable products on the shelf by placing all items from a sustainable brand together can also stimulate their market share. The impact of shelf arrangement also goes beyond the location of the sustainable brands themselves; the arrangement of the entire product category has a significant relationship with the market share of especially organic brands. An assortment arrangement that emphasizes unique aspects of different brands (i.e., arranged by brand) is associated with higher market share for organic brands.

In our study, it appears that price promotions do not have a strong relationship with sales of sustainable products. In other words, the demand for sustainable products does not appear very sensitive to price promotions, which is in line with prior research (Arnot et al. 2006; Ngobo 2011). Yet, the price level is not irrelevant to buyers of fair trade products. When the price premium for fair trade brands is higher, their market share is lower. For organic products, price does not significantly affect market share, which is in line with the idea that a higher price can signal quality and stimulate consumers to recategorize organic products as health food (Wathieu and Bertini 2007), thus counteracting the negative consequences of high prices for these products.

These results have important implications for retailers who want to stimulate sales of organic and fair trade brands. To stimulate such sales, placement at eye level and clustering of products are relevant for both organic and fair trade brands. The amount of shelf facings, however, is mostly relevant for fair trade brands. Thus, whereas the predominant focus has long been on the battle for shelf space, our study indicates that a battle for shelf position is relevant as well. The location of a product 
on the shelf may be just as, or even more, important than how many facings it receives. Simply rearranging, rather than redistributing shelf space thus could increase the market share of sustainable brands. Moreover, arranging products from a category on brand can stimulate the sales of organic (but not fair trade) brands.

Another implication of our study is that in order to increase sales of sustainable products, retail chains should take the socio-demographic characteristics of the service area into account, as higher sales of sustainable products are found in areas where the customer base is older and/or has higher education. The results appear to indicate that these effects may be stronger for fair trade rather than organic products, which is surprising given the more diverse consumer base typically associated with fair trade buyers (De Pelsmacker and Janssens 2007; Lamb 2007). Future research may examine this further.

The results also show that fair trade products are more responsive than organic products to changes in shelf facings, but not to changes in (vertical) shelf position or clustering. We had expected that the greater importance of visibility for fair trade products would lead to a greater responsiveness to each of these marketing mix instruments. An explanation might be that different processes are involved. The position of a product at eye level may not only increase its visibility, but the prime location may also signal retailer support and quality to consumers. Likewise, clustering of products may emphasize the variety that is offered within the brand. Given that the brand assortment is especially important for sustainable products (Bezawada and Pauwels 2010), raising consumer awareness of the options available from sustainable brands may be a different way in which product clustering affects market share.

Finally, our study has several limitations that might inspire further research. We did not have access to sales and price promotions data over time. More details about the timing of price promotions and the corresponding sales levels could improve the estimation of the effects of such promotions. As our study focused on organic and fair trade products, additional research could also compare the effectiveness of marketing mix instruments between these products and either conventional products or products carrying both organic and fair trade labels. We hope that more research will investigate the effects of marketing instruments for sustainable products, taking into account that not all sustainable products are alike.

Acknowledgements The authors thank Jean-François Louisa for help in data collection and Super de Boer N.V. for its support. The authors also acknowledge the support of TransForum (Veldkamp et al. 2009; DOI: 10.1051/agro:2008022), an innovation program for the Dutch agricultural sector. The authors thank Peter Verhoef, Koen Pauwels, Hans van Trijp, Marcel Kornelis and Arnout Fischer for their feedback on prior versions of this article.

Open Access This article is distributed under the terms of the Creative Commons Attribution Noncommercial License which permits any noncommercial use, distribution, and reproduction in any medium, provided the original author(s) and source are credited.

\section{References}

Ailawadi, K. L., Gedenk, K., Lutzky, C., \& Neslin, S. A. (2007). Decomposition of the sales impact of promotion-induced stockpiling. Journal of Marketing Research, 44(3), 450-467. 
Ajzen, I., Brown, T. C., \& Carvajal, F. (2004). Explaining the discrepancy between intentions and actions: the case of hypothetical bias in contingent valuation. Personality and Social Psychology Bulletin, 30 (9), 1108-1121.

Areni, C. S., Duhan, D. F., \& Kiecker, P. (1999). Point-of-purchase displays, product organization, and brand purchase likelihoods. Journal of the Academy of Marketing Science, 27(4), 428-441.

Arnot, C., Boxall, P. C., \& Cash, S. B. (2006). Do ethical consumers care about price? A revealed preference analysis of fair trade coffee purchases. Canadian Journal of Agricultural Economics, 54(4), 555-565.

Auger, P., Devinney, T. M., Louviere, J. J., \& Burke, P. F. (2008). Do social product features have value to consumers? International Journal of Research in Marketing, 25(3), 183-191.

Bezawada, R., \& Pauwels, K. H. (2010). Are organics that special? Managing organic and conventional products across categories. Istanbul: Working paper, Ozyegin University.

Boatwright, P., \& Nunes, J. C. (2001). Reducing assortment: an attribute-based approach. Journal of Marketing, 65(July), 50-63.

Bowes, J., \& Croft, D. (2007). Organic and fair trade crossover and convergence. In S. Wright \& D. McCrea (Eds.), The handbook of organic and fair trade food marketing (pp. 262-283). Oxford: Blackwell.

Campo, K., \& Gijsbrechts, E. (2005). Retail assortment, shelf and stockout management: issues, interplay and future challenges. Applied Stochastic Models in Business and Industry, 21(4-5), 383-392.

Campo, K., Gijsbrechts, E., Goossens, T., \& Verhetsel, A. (2000). The impact of location factors on the attractiveness and optimal space shares of product categories. International Journal of Research in Marketing, 17(4), 255-279.

Chandon, P., Hutchinson, J. W., Bradlow, E. T., \& Young, S. H. (2009). Does in-store marketing work? Effects of the number and position of shelf facings on brand attention and evaluation at the point of purchase. Journal of Marketing, 73(6), 1-17.

Chung, C., Schmit, T. M., Dong, D., \& Kaiser, H. M. (2007). Economic evaluation of shelf-space management in grocery stores. Agribusiness, 23(4), 583-597.

Cottingham, M., \& Winkler, E. (2007). The organic consumer. In S. Wright \& D. McCrea (Eds.), The handbook of organic and fair trade food marketing (pp. 29-53). Oxford: Blackwell.

De Pelsmacker, P., \& Janssens, W. (2007). A model of fair trade buying behavior: the role of perceived quantity and quality of information and of product-specific attitudes. Journal of Business Ethics, 75 (4), 361-380.

De Pelsmacker, P., Driesen, L., \& Rayp, G. (2005a). Do consumers care about ethics? Willingness to pay for fair-trade coffee. The Journal of Consumer Affairs, 39(2), 363-385.

De Pelsmacker, P., Janssens, W., Sterckx, E., \& Mielants, C. (2005b). Consumer preferences for the marketing of ethically labelled coffee. International Marketing Review, 22(5), 512-530.

Desmet, P., \& Renaudin, V. (1998). Estimation of product category sales responsiveness to allocated shelf space. International Journal of Research in Marketing, 15(5), 443-457.

Desrochers, D. M., \& Nelson, P. (2006). Adding consumer behavior insights to category management: improving item placement decisions. Journal of Retailing, 82(4), 357-365.

Doran, C. J. (2009). The role of personal values in fair trade consumption. Journal of Business Ethics, 84 (4), 549-563.

Drèze, X., Hoch, S. J., \& Purk, M. E. (1994). Shelf management and space elasticity. Journal of Retailing, 70(4), 301-326.

Erdem, T. (1998). An empirical analysis of umbrella branding. Journal of Marketing Research, 35(3), 339-351.

Erdem, T., \& Swait, J. (2004). Brand credibility, brand consideration, and choice. Journal of Consumer Research, 31(1), 191-198.

Erdem, T., Keane, M. P., \& Sun, B. (2008). A dynamic model of brand choice when price and advertising signal product quality. Marketing Science, 27(6), 1111-1125.

Haanpää, L. (2007). Consumers' green commitment: indication of a postmodern lifestyle? International Journal of Consumer Studies, 31(5), 478-486.

Just-Food. (2004). The ethical foods retailer, October, 37.

Kahn, B., \& Wansink, B. (2004). The influence of assortment structure on perceived variety and consumption quantities. Journal of Consumer Research, 30(March), 519-533.

Lamb, H. (2007). The fair trade consumer. In D. McCrea \& S. Wright (Eds.), The handbook of organic and fair trade food marketing (pp. 54-81). Oxford: Blackwell.

Lim, A., Rodrigues, B., \& Zhang, X. (2004). Meta-heuristics with local search techniques for retail shelfspace optimization. Management Science, 50(January), 117-131.

Loureiro, M., \& Lotade, J. (2005). Do fair trade and eco-labels in coffee wake up the consumer conscience? Ecological Economics, 53(1), 129-138. 
Ngobo, P. V. (2011). What drives household choice of organic products in grocery stores? Journal of Retailing, 87(1), 90-100.

Roberts, J. A. (1996). Green consumers in the 1990s: profile and implications for advertising. Journal of Business Research, 36(3), 217-231.

Schifferstein, H. N. J., \& Oude Ophuis, P. A. M. (1998). Health-related determinants of organic food consumption in the Netherlands. Food Quality and Preference, 9(3), 119-133.

Sustainable Development Commission (2008). www.sd-commission.org.uk/publications/downloads/ GreenHealthyAndFair.pdf.

Tanner, C., \& Wölfing Kast, S. (2003). Promoting sustainable consumption: determinants of green purchases by Swiss consumers. Psychology \& Marketing, 20(10), 883-902.

Thompson, G. D. (1998). Consumer demand for organic foods: what we know and what we need to know. American Journal of Agricultural Economics, 80(5), 1113-1118.

Van Dijk, A., van Heerde, H. J., Leeflang, P. S. H., \& Wittink, D. R. (2004). Similarity-based spatial methods to estimate shelf space elasticities. Quantitative Marketing and Economics, 2(3), 257-277.

Van Herpen, E., \& Pieters, R. (2002). The variety of an assortment: an extension to the attribute-based approach. Marketing Science, 21, 331-341.

Van Nierop, E., Fok, D., \& Frances, P. H. (2008). Interaction between shelf layout and marketing effectiveness and its impact on optimizing shelf arrangements. Marketing Science, 27(6), 1065-1082.

Verhoef, P. C. (2005). Explaining purchases of organic meat by Dutch consumers. European Review of Agricultural Economics, 32(2), 245-267.

Vermeir, I., \& Verbeke, W. (2006). Sustainable food consumption: exploring the consumer "attitudebehavioral intention" gap. Journal of Agricultural and Environmental Ethics, 19(2), 169-194.

Wathieu, L., \& Bertini, M. (2007). Price as a stimulus to think: the case for willful overpricing. Marketing Science, 26(1), 118-129.

Wier, M., \& Calverley, C. (2002). Market potential for organic foods in Europe. British Food Journal, 104 (1), 45-62.

Yoo, B., Donthu, N., \& Lee, S. (2000). An examination of selected marketing mix elements and brand equity. Journal of the Academy of Marketing Science, 28(2), 195-211.

Zhang, F., Huang, C. L., Lin, B., \& Epperson, J. E. (2008). Modeling fresh organic produce consumption with scanner data: A generalized double hurdle model approach. Agribusiness, 24(4), 510-522. 